Review Article

\title{
A Review on Synthesis, Optimization, Mechanism, Characterization, and Antibacterial Application of Silver Nanoparticles Synthesized from Plants
}

\author{
Sunday Adewale Akintelu $\mathbb{D}^{1,2}$ Yao Bo, ${ }^{1}$ and Aderonke Similoluwa Folorunso $\mathbb{D}^{3}$ \\ ${ }^{1}$ MOE Key Laboratory of Cluster Science, Beijing Key Laboratory of Photoelectronic Electrophotonic Conversion Materials, \\ School of Chemistry and Chemical Engineering, Beijing Institute of Technology, Beijing 102488, China \\ ${ }^{2}$ Department of Pure and Applied Chemistry, Ladoke Akintola University of Technology, Ogbomoso, Nigeria \\ ${ }^{3}$ Department of Chemistry, Louisiana State University, Baton Rouge, Louisiana, USA
}

Correspondence should be addressed to Sunday Adewale Akintelu; akintelusundayadewale@gmail.com and Aderonke Similoluwa Folorunso; folorunsoaderonkesimi@gmail.com

Received 13 August 2020; Revised 2 November 2020; Accepted 18 November 2020; Published 5 December 2020

Academic Editor: Gabriel Navarrete-Vazquez

Copyright (c) 2020 Sunday Adewale Akintelu et al. This is an open access article distributed under the Creative Commons Attribution License, which permits unrestricted use, distribution, and reproduction in any medium, provided the original work is properly cited.

\begin{abstract}
Developments in nanotechnology and natural product research toward the search for novel antibacterial agents have drawn the interest of many scientists to the synthesis of silver nanoparticles (AgNPs) from natural product (especially plants) due to its numerous benefits over other methods of synthesis such as been easy, economical, convenient, and environmental friendly. Aside from the aforementioned advantages, the synthesis of AgNPs from medicinal plant has been reported as the best approach of synthesizing AgNPs with great biological activities due to the numerous biomolecules found in plants. Recently, the number of researches toward the improvement of the yield, morphological properties, analytical techniques, and the development of optimal conditions and exact mechanism for synthesizing AgNPs from plants have been increasing tremendously. In this review, we present a comprehensive report on the recent development in the synthesis, optimization conditions, mechanism, and characterization techniques of AgNPs synthesized from plant extracts. Furthermore, a thorough discussion on the recent advances in the application of AgNPs synthesized from plant as therapeutic agent against bacterial infections was made.
\end{abstract}

\section{Introduction}

Bacterial infections had remained a major threat facing medical industry since the occurrence of antibiotic-resistant bacterial strains [1]. The overdosage of antibiotics in treating infectious diseases coupled with other side effects (like strain, diagnosis, and treatment, hypersensitivity, immunesuppression, and allergic effects) has been linked to the causes of drug resistance. Reports on the usage of AgNPs as a therapeutic agent in curing bacterial infection or as an alternative to antibiotic drugs showed good effect on multidrug resistant bacteria [2]. The presence of protein caps on AgNPs has been observed to be a great advantage in promoting the binding and stabilization on bacterial cell surface which promote the binding and absorption of drug on human cells [3].

Nanotechnology is the scientific approach of synthesizing particles of nanoscale in the range of 1 to $100 \mathrm{~nm}$ [4]. The large surface area to volume ratio exhibited by nanoparticles has been reported to enhance their optical properties to confine their electrons and yield quantum effects that are easily detectable. Diverse application of AgNPs in pesticide [5, 6], food sensing [7], textile [8], medical [9], DNA detection [10], water [11] and pharmaceutical industries has been reported to increase its demand.

Limitation of the chemical method of synthesizing AgNPs has been traced down to the health and environmental implications associated with the organic solvents 
such as ascorbate, trisodium citrate, hydrazine, sodium borohydride, and sodium borohydride used as reducing and stabilizing agent in chemical synthesis of AgNPs [12]. In addition, literatures had also made it clear that chemical reduction method also produces low yield, high purity, require high energy, and expensive $[13,14]$.

Quest to eradicate this problem as demand for AgNPs increases had led to the synthesis of AgNPs from biological substances (microorganisms and plants). Intracellular and extracellular synthesis of AgNPs from microbes such as Penicillium oxalicum GRS-1 [15], Aspergillus fumigatus BTCB10 [16], and Trichoderma longibrachiatum [17] have been documented. However, the following set back was recorded; expensive cost of isolation, difficulties in maintaining aseptic conditions, culture media, and toxicity of some microorganism [18].

It is worth knowing that the phytosynthesis of AgNPs puffer solution to the limitations associated with both the chemical and microbial methods of synthesis because the reduction process and mechanism of phytosynthesis of AgNPs are based on the biomolecules found in the plant extract; therefore, they are said to be cheap, environmental friendly, easy, and cost-effective [19]. The following biomolecules: terpenoids, carbohydrates, tannins, fats, enzymes, flavonoids, and phenols have been reported proficient for the reduction of silver to nanoparticles [20].

\section{Synthesis of AgNPs from Plants}

In synthesis of AgNPs from plant encourage large-scale production of AgNPs, which is a remedy to the high demand of AgNPs, plant leaf is more preferable than the whole plant in the synthesis of extracellular AgNPS [21]. Plant extract possesses diverse active biomolecules such as phenolic acids, sugars, terpenoids, alkaloids, polyphenol, and proteins that play vital role in this biological reduction and stabilization of silver ions [22]. The structure of some active biomolecules that are capable of reducing and stabilizing silver ions are shown in Table 1. The size and shape of AgNPs depend on the following parameters: volume of plant extract used, concentration of silver, temperature, reaction time, and $\mathrm{pH}$ value of the reaction [23]. The procedure for the synthesis of AgNPs entails collection and identification of plants part (seeds, fruits, leaves, rhizomes, roots, barks, pulps, stem, pod, and latex), purification of plant parts by sorting and washing, drying of plants parts at room temperature to prevent evaporation of volatile biomolecules, pulverization of dried plant parts to aid rapid extraction, extraction with water or other solvent at minimum temperature if heat is required, preparation of silver salt usually in concentration of 1-5 mM, and combination of plants extract with prepared silver salt in ratio of $1: 5$. Application of minimal heat to the mixture with continuous stirring until a color change has been observed; finally, the solution will be filtered and incubated [24]. Report has shown that the biosynthesis of AgNPs could be completed in the silver salt solution within minutes at temperature of $25^{\circ} \mathrm{C}$; however, the types of secondary metabolites present in plant extract have a great significance effect. Also, the concentration of the extract,
TABLE 1: Structures of some secondary metabolites used as stabilizing and reducing agents in AgNPs synthesis.

Structures of some secondary metabolites used as stabilizing and reducing agents in AgNPs synthesis

\begin{tabular}{lcc}
\hline Rutin & Genistein & Quercetin \\
Gallic acid & Daldzein & Papaverine \\
\hline
\end{tabular}

concentration of silver salt, temperature, $\mathrm{pH}$, and contact time matter [25]. The chemical and physical methods are equally employed in the synthesis of AgNPs. The chemical synthesis entails the use of some hazardous chemicals and reagents which can cause some health and environment implications for the reduction of the silver ions and stabilization of formed nanoparticles, while the physical method makes use of electric current in generation of electron needed for AgNPs synthesis. Electrospraying, laser pyrolysis, laser ablation, and evaporation-condensation rampantly used physical methods of AgNPs synthesis [26-28]. The flow chart illustrating the synthesis of AgNPs is given in Figure 1.

\section{Optimization Conditions for the Synthesis of AgNPs from Plants Extract}

The roles of reaction parameters are very imperative in optimizing the size, stability, and yield of biosynthesized AgNPs. Alteration of concentration of the plant extract, $\mathrm{pH}$, time of incubation, concentration of silver salt, and temperature has been reported as good optimizing condition for the synthesis of AgNPs [29]. Properties of AgNPs greatly depend on optimization conditions. Many researchers had reported $\mathrm{pH}$ values in the range of 2 to 14 for AgNPs synthesis [13]. Nevertheless, a $\mathrm{pH}$ value of 7 has been reported as an optimal condition for monitoring the complete reduction of $\mathrm{Ag}^{+}$to $\mathrm{Ag}^{0}$ during the synthesis of AgNPs using Pinus eldarica bark extract [30]. Also maximum nanoparticles synthesis occurred between $\mathrm{pH}$ of 7 and 9 during the synthesis of AgNPs using Fusarium oxysporum [31]. The synthesis of AgNPs can be attained at different temperatures but $25^{\circ} \mathrm{C}$ (room temperature) has been documented as optimal for the synthesis of small size and spherical AgNPs [32]. Maximum yield of biosynthesized AgNPs was recorded at room temperature using aqueous Aloe barbadensis leaf extract [3]. Similar result was obtained from the synthesis of AgNPs using Annona squamosa peel extract [33]. Temperature has been found to be a good parameter in determining the nature of peaks of synthesized AgNPs, and low temperature corresponds to sharp peaks, while higher temperature is associated with broad peaks. The synthesis of AgNPs using the Aspergillus fumigatus revealed maximum yield and desired particle size of $322.8 \mathrm{~nm}$ with sharp peaks at $25^{\circ} \mathrm{C}$. With an increase in temperature, AgNPs with increased size and broad peaks were produced [16]. Concentration of silver salt played vital role in estimating the level of agglomeration in the synthesis of AgNPs and concentration above $10 \mathrm{mM}$ resulted in increase in the surface plasmon resonance (SPR) band, agglomeration buildup of silver, and blurred surfaces. A period of 10 minutes has been regarded as the optimal incubation time for the AgNPs [34]. 


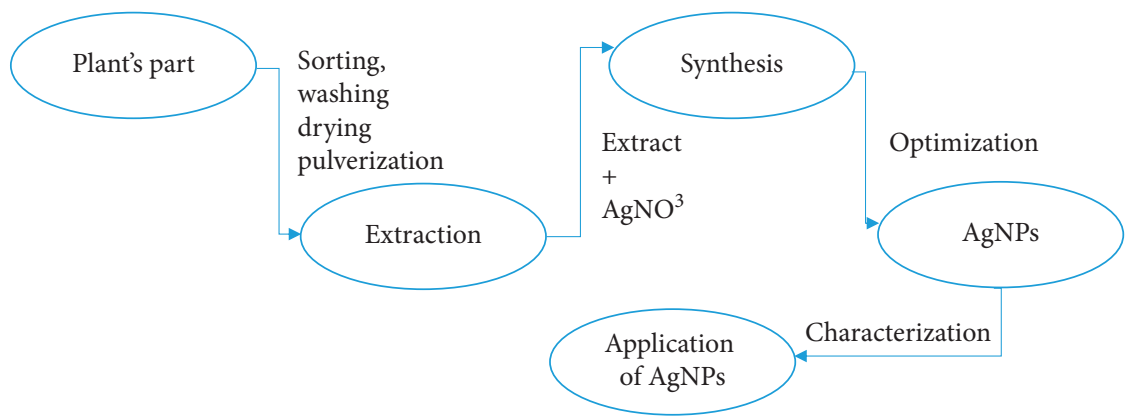

FIgURE 1: Flow chart illustrating the synthesis of AgNPs.

\section{Mechanism of AgNPs Synthesis}

The biosynthesis of AgNPs is a simple and facile method achieved by mixing silver nitrate $\left(\mathrm{AgNO}_{3}\right)$ with biological substances usually microorganism (fungi, bacterial and algae) or extract from plant's part serving as the capping and stabilizing agents [35]. The reduction and stabilization of silver ions from $\mathrm{Ag}^{+}$to $\mathrm{Ag}^{0}$ has been traced to the presence of $\mathrm{OH}$ functional groups in plants biomolecules such as proteins, amino acids, enzymes, steroids, alkaloids, polyphenols, quinones, tannins, saponins, carbohydrates, flavonoids, and vitamins in plants extracts or microorganism $[35,36]$, though the right mechanism involved in the reduction and stabilization of silver ions has not been clearly understood because biomolecules varies from plant to plants, hence, the complexity of the mechanism because 4000 phytochemicals had been known in plants [36]. Therefore, the synthesis of AgNPs from plants needs more detailed research as to divulge the appropriate biomolecules serving as the capping and stabilizing agent. Nevertheless, numerous plants are described to support the synthesis AgNPs. Some of such plants are documented in Table 2.

The illustration of the possible mechanism involved in the synthesis of AgNPs from plant extract is given in Figure 2. The conversion of the hydroxyl groups from a secondary metabolite quercetin (2-(3,4-dihydroxyphenyl)-3,5,7- trihydroxy-4H-chromen-4-one) usually found in plant extract to the 3,5,7-trihydroxy-2-(4-hydroxy-3-oxocyclohexa-1,5-dien-1yl)- $4 \mathrm{H}$-chromen-4-one generates reducing equivalents that are used for the conversion of silver metal ions $\left(\mathrm{Ag}^{+}\right)$into elemental $\left(\mathrm{Ag}^{0}\right)$ nanostructures [36]. This usually accomplished a color change during nanoparticles synthesis.

\section{Characterization of AgNPs Synthesized from Plants}

Characterization is required for determination of the structural and morphological properties of AgNPs. The major techniques used for the characterization of AgNPs are $X$-ray diffraction (XRD) for identification of the crystalline or amorphous natures of AgNPs, scanning, and transmission electron microscopy (SEM) for evaluation of size and morphology of synthesized AgNPs; Fourier transform infrared (FTIR) is used for identification of functional groups used in reduction of silver salt. For each of the characterization techniques, a different method of sample preparation is required [64].

\section{XRD Analysis}

$\mathrm{XRD}$ analysis determines the crystallite size of AgNPs. This is achieved with Philips diffractometer of ' $X$ ' pert company and a nanochromatic $\mathrm{Cu} \mathrm{K} \alpha$ radiation of $(\lambda=1.54060 \mathrm{~A})$ radiation. The width of XRD peaks is used for the size determination following Scherrer's formula, $D=0.86 \lambda / \beta \cos \theta$. The three diffraction peaks of (111), (200), and (220) represent the facecentered cubic silver. The sharpness of these peaks illustrates formation of particles the nanosize [64]. Another study also reported the indexing peak of AgNPs displayed strong Braggs reflection which correspond to the reflections of face centered cubic of silver as shown in Figure 3.

\section{Scanning Electron Microscope (SEM)}

This technique is used to study the size and shape of the nanoparticles. In SEM technique, electrons are used for the formation of an output image instead of light [66]. The synthesized AgNps is placed on a stub made for SEM analysis. The stub is usually made up of small cylinder copper of $1 \mathrm{~mm}$ diameter. One layer of the stub contains carbon. When the synthesized AgNps is placed on the carbon material, the stub is attached to a holder. The holder can take up to seven samples [63]. A spherical, hexagonal, round, oval, cuboidal, and triangular shape of AgNPs has been detected using the SEM techniques as shown in Table 2. An example of SEM microgram of synthesized AgNPs is shown in Figure 4. Aside from the morphological assessment of AgNPs, SEM analysis can also be useful for the estimation of stability of AgNPs; SEM analysis of AgNPs synthesized from Carica papaya leaf extract showed that increase in concentration of plant extract led to agglomeration and destabilization of AgNPs [67].

\section{Fourier-Transform Infrared (FTIR) Spectroscopic Technique}

FTIR technique is useful for the determination of the functional groups in the plants biomolecules that are responsible for the reduction and stabilization of the silver ion. For FTIR analysis, synthesized AgNPs and plant extract could be in the solid or liquid state. The dry method of analysis synthesized AgNPs and plant extract was carried out by mixing $1 \%(\mathrm{w} / \mathrm{w})$ AgNPs and plant extract with $100 \mathrm{mg}$ of potassium bromide powder separately. The mixture was properly pressed into a sheer slice and was scanned by on 
TABle 2: Characterization of AgNPs synthesized from plants extracts.

\begin{tabular}{|c|c|c|c|c|c|c|c|}
\hline $\begin{array}{l}\mathrm{S} / \\
\mathrm{N}\end{array}$ & Scientific names & $\begin{array}{l}\text { Plants } \\
\text { extract }\end{array}$ & $\begin{array}{l}\text { Wavelength } \\
\text { (nm) }\end{array}$ & Techniques used & Shape & Size $(\mathrm{nm})$ & Ref \\
\hline 1 & Artemisia vulgaris $\mathrm{L}$. & Leaf & 420 & UV, FTIR, AFM, SEM and TEM & Round & 25 & {$[37]$} \\
\hline 2 & Mentha spicata & Leaf & 460 & UV, FTIR, SEM and XRD & Spherical & 44.98 & [38] \\
\hline 3 & Oryza sativa & Husk & 425 & UV, FTIR and SEM & Spherical & 47.90 & [39] \\
\hline 4 & Carica papaya & Peel & 435 & UV, FTIR, XRD, SEM and TEM & Spherical & 20.10 & {$[40]$} \\
\hline 5 & Coriandrum sativum & Leaf & 316 & UV, FTIR, XRD, SEM & Spherical & 6.45 & [41] \\
\hline 6 & Eriobotrya japonica & Leaf & 469 & TEM, FESEM, and SAED & Spherical & $3-30$ & {$[42]$} \\
\hline 7 & Ocimum tenuiflorum & Leaf & 420 & UV, FTIR, AFM, SEM, and XRD & Spherical & 28 & [43] \\
\hline 8 & Solanum trilobatum & Leaf & 423 & UV, FTIR, AFM, SEM, and XRD & Spherical & 26.5 & [43] \\
\hline 9 & Syzygium cumini & Leaf & 422 & UV, FTIR, AFM, SEM, and XRD & Spherical & 65 & [43] \\
\hline 10 & Centella asiatica & Leaf & 421 & UV, FTIR, AFM, SEM, and XRD & Spherical & 22.3 & [43] \\
\hline 11 & Citrus sinensis & Peel & 420 & UV, FTIR, AFM, SEM, and XRD & Spherical & 28.4 & [43] \\
\hline 12 & Salvia spinosa & Seed & 450 & UV, FTIR, XRD and FESEM & Oval & $19-25$ & [27] \\
\hline 13 & Morus nigra & Leaf & 430 & UV, FTIR, XRD and TEM & Spherical & $15-20$ & [44] \\
\hline 14 & Silybum marianum & Fruit & 425 & UV, FTIR, XRD and TEM & Spherical & 25 & {$[45]$} \\
\hline 15 & Berberis vulgaris & Leaf & 450 & UV, FTIR, XRD, DLS and TEM & Spherical & $30-70$ & [46] \\
\hline 16 & Quercus brantii & Leaf & 435 & UV, FTIR and TEM & Spherical & 6 & [47] \\
\hline 17 & Prunus japonica & Leaf & 425 & UV, FTIR and SEM & Hexagonal & 26 & [48] \\
\hline 18 & Pistacia atlantica & Seed & 438 & UV, FTIR, XRD, and TEM & Spherical & $10-50$ & [49] \\
\hline 19 & Catharanthus roseus & Root & 429 & UV, FTIR, XRD and TEM & Spherical & $35-55$ & [50] \\
\hline 20 & $\begin{array}{c}\text { Rumex } \\
\text { hymenosepalus }\end{array}$ & Root & 456 & UV, FTIR, XRD and TEM & Hexagonal & $2-40$ & [51] \\
\hline 21 & Aloe vera & Leaf & 430 & UV, FTIR, XRD and TEM & Triangular & 70 & {$[52]$} \\
\hline 22 & Calotropis procera & Latex & 454 & UV, FTIR and SEM & Spherical & 12.33 & [53] \\
\hline 23 & Acorus calamus & Rhizome & 437 & UV-Vis, DLS, SEM, XRD, FTIR & Cuboidal & 59 & [54] \\
\hline 24 & Erythrina indica & Root & 460 & UV-Vis, DLS, EDX, SEM, XRD, FTIR & Spherical & $20-118$ & {$[55]$} \\
\hline 25 & Cymodocea serrulata & Leaf & 454 & UV-Vis, DLS, TEM, SEM, XRD, FTIR & Spherical & 29.28 & [56] \\
\hline 26 & Dimocarpus longan & Peel & 432 & TEM, SEM & Spherical & $8-22$ & [57] \\
\hline 27 & Cymodocea serrulata & Whole plant & 441 & UV-Vis, DLS, EDX, SEM, XRD, FTIR & Spherical & $17-29$ & [58] \\
\hline 28 & Quercus acuta & Fruit & 421 & UV-Vis, SEM, TEM, XRD, FTIR, DLS & Spherical & 40 & [59] \\
\hline 29 & Rubus glaucus Benth & Leaf & 422 & UV-Vis, TEM, SEM, FTIR, XRD & $\begin{array}{c}\text { Quasi } \\
\text { spherical }\end{array}$ & $12-50$ & {$[60]$} \\
\hline 30 & Plumeria alba & Flower & 436 & UV-Vis, DLS, SEM, & Spherical & 36.19 & [61] \\
\hline 31 & Rosa damascena & Petal & 429 & $\begin{array}{c}\text { UV-Vis, TEM, SEM, FTIR, XRD, } \\
\text { EDX }\end{array}$ & Spherical & $15-27$ & {$[62]$} \\
\hline 32 & Rosa indica & Petal & 415 & $\begin{array}{c}\text { UV-Vis, TEM, SEM, FTIR, XRD, } \\
\text { EDX }\end{array}$ & Spherical & $23.52-60.83$ & {$[63]$} \\
\hline
\end{tabular}

$[\mathrm{AFM}=$ atomic force microscopy, FESEM = field emission scanning electron microscopy, SEAD = selected area electron diffraction, DLS = dynamic light scattering, and UV-Vis = ultraviolet-visible].

FTIR spectrometer (FTIR Nicolet 5700, Thermo Corp. USA) at a resolution of $2 \mathrm{~cm}^{-1}$ [65]. The FTIR analysis of synthesized AgNPs and plant extract had revealed that functional groups such amides and amino carboxyl are responsible for the stabilization of synthesized AgNPs [68-71]. The FTIR spectrum illustrating that plant extract contained some biomolecules is shown in Figure 5.

\section{Transmission Electron Spectroscopy (TEM)}

Determination of size distribution of AgNPs is very vital because they possess different physical and chemical features depending on their shape and size [73]. In the preparation of AgNPs for TEM analysis, small amount of AgNPs is placed on carbon coated copper grids. A ray of photons is transmitted through an ultrathin dried grid containing the AgNPs and interacting with it as it passes through [22]. The electrons are transmitted through the AgNPs to produce an interaction that results in the formation of an image. The image is magnified and recorded by an imaging device [74]. The use of medicinal plants for the synthesis of AgNPs is not only for the enhancement of their antimicrobial properties but also to regulate the size and shape of AgNPs [37]. Numerous plant extracts have been used for the synthesis of AgNPs and different morphologies have been obtained in Table 2. SEM microgram showing a spherical shape synthesized nanoparticles is shown in Figure 6.

\section{UV-Vis Spectroscopy}

The UV-Vis spectroscopy is used to measure the plasmon absorbance responsible for characteristic colors observed during the synthesis of AgNPs. The absorption of the electrons on the surface of AgNPs and electromagnetic radiation by incident light produces oscillations. The absorption maximum for AgNPs has been reported to be in the range 0.5 and 0.7 . The plasmon resonance produces a peak near $400 \mathrm{~nm}$ which confirmed the synthesis of AgNPs [71]. 


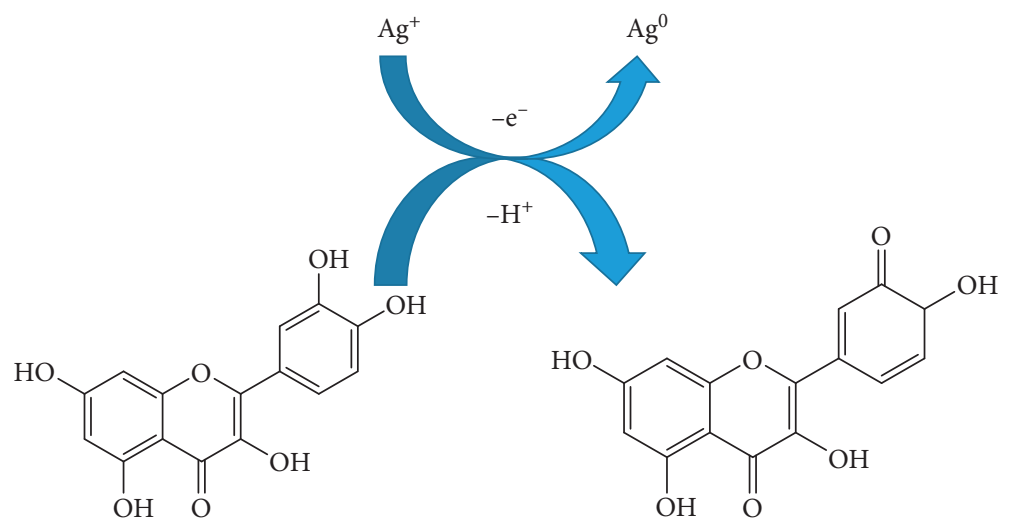

2-(3,4-Dihydroxyphenyl)-3,5,7trihydroxy-4H-chromen-4-one
3,5,7-Trihydroxy-2-(4-hydroxy-3-oxocyclohexa1,5-dien-1-yl)-4H-chromen-4-one

Figure 2: The proposed mechanism for the synthesis of AgNPs.

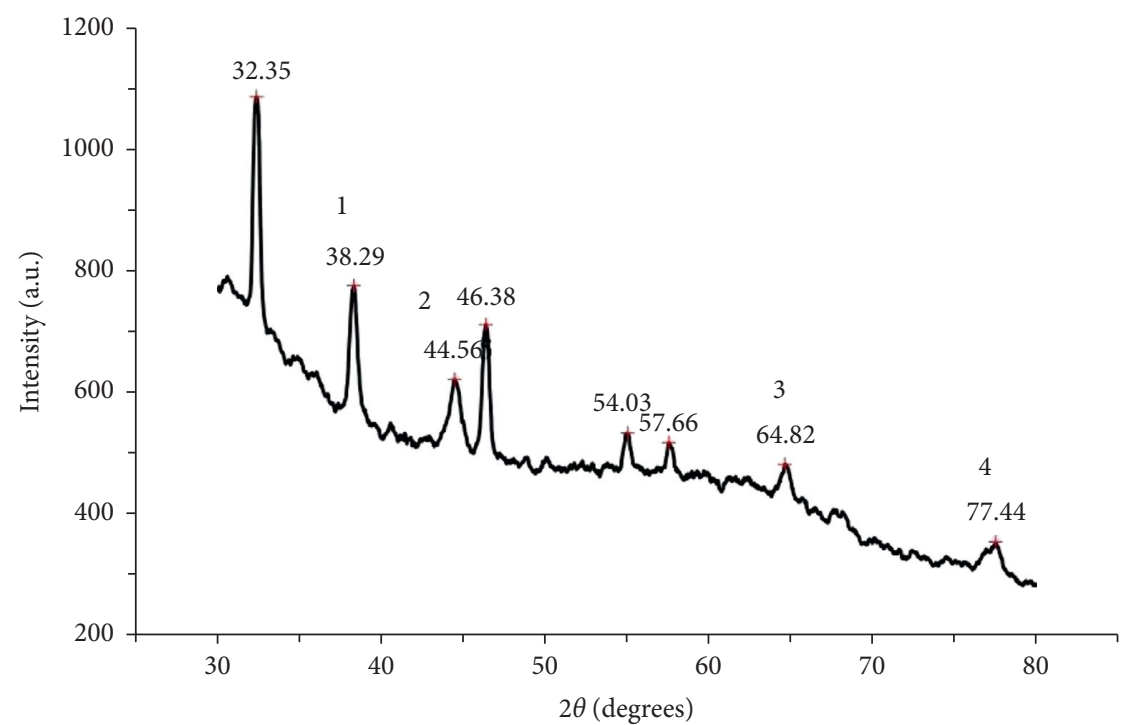

FIGURE 3: XRD micrograph of the synthesized silver nanoparticles Adapted from [65].

The UV-Vis spectroscopic analysis of AgNPs synthesized from plant and their corresponding plasmon resonance peaks are shown in Figure 7 and Table 1.

\section{Energy-Dispersive X-Ray Spectroscopy}

The elemental composition of synthesized AgNPs is determined with the energy-dispersive $\mathrm{X}$-ray technique [76]. The working principle of an energy-dispersive $\mathrm{X}$-ray is based on the collision of electrons with the nanoparticles to produce $\mathrm{X}$-rays, the uniqueness of the atomic structure of each element in making a distinct set of peaks on its X-ray spectrum results to the characterization of the elements. The distinct peak at $2.8-3.2 \mathrm{keV}$ on the EDX is associated with the presence of silver [77]. EDX analysis of AgNPs shown in Figure 8 revealed an optical absorption peak at $3 \mathrm{keV}$ [75].

\section{Antibacterial Activity of Silver Nanoparticles}

Recently, the increase in antibiotic-resistant microbes is becoming alarming and worrisome, and certain pathogens associated with some infections which increase the mortality rate in human and method of treatment with available antibiotic are proving abortive cost. Therefore, the need to 


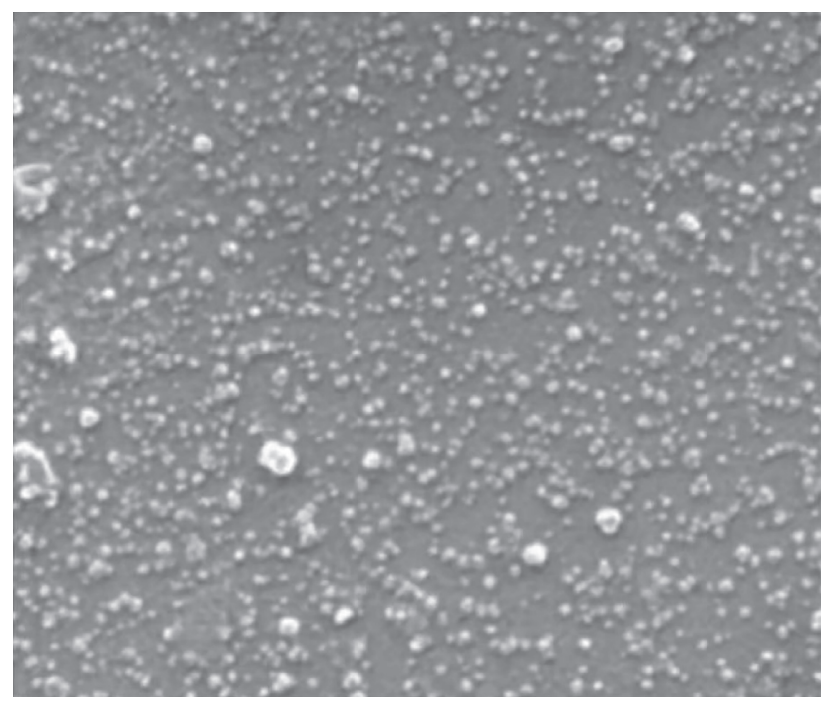

FIGURE 4: SEM micrograph of the synthesized silver nanoparticles adapted from [28].

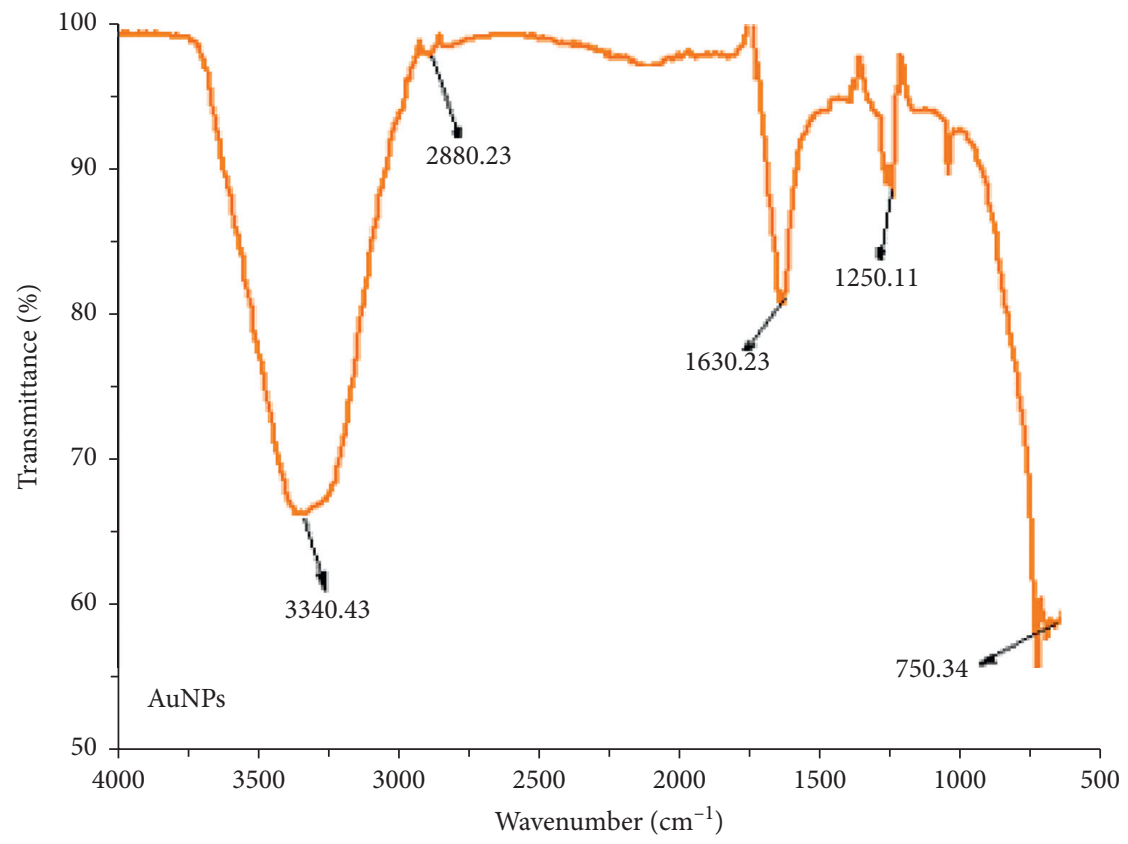

FIGURE 5: FTIR spectrum of synthesized silver nanoparticles adapted from [72].

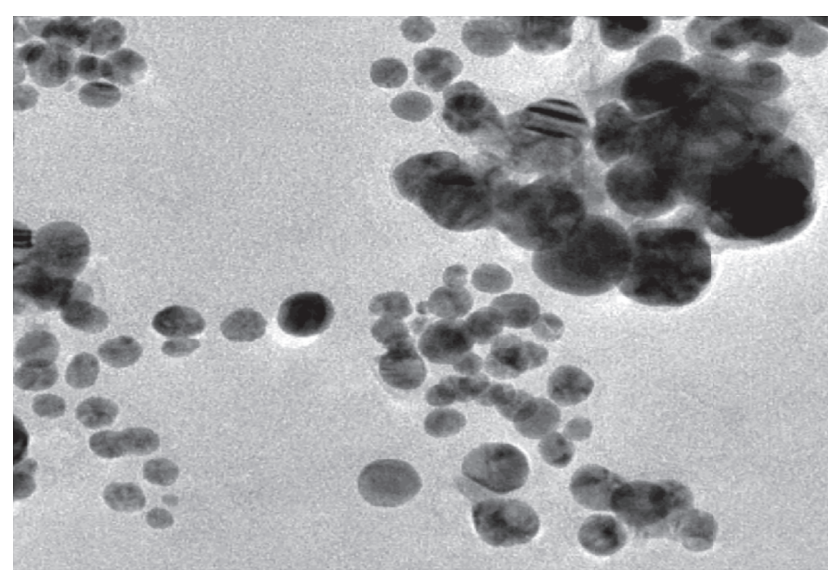

FIGURE 6: TEM micrograph of the synthesized silver nanoparticles adapted from [72]. 


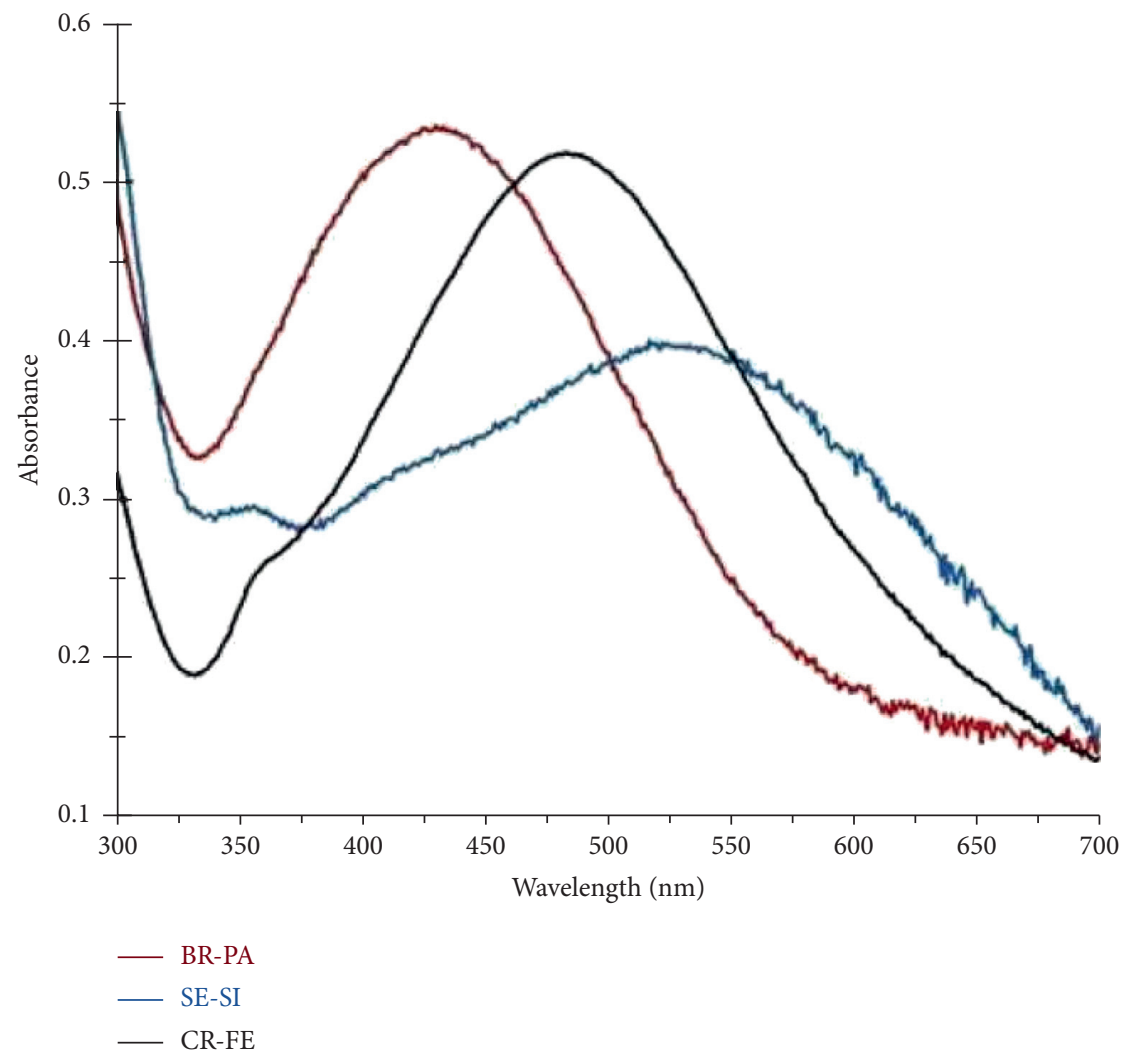

FIGURE 7: UV spectrum of the synthesized silver nanoparticles adapted from [75].

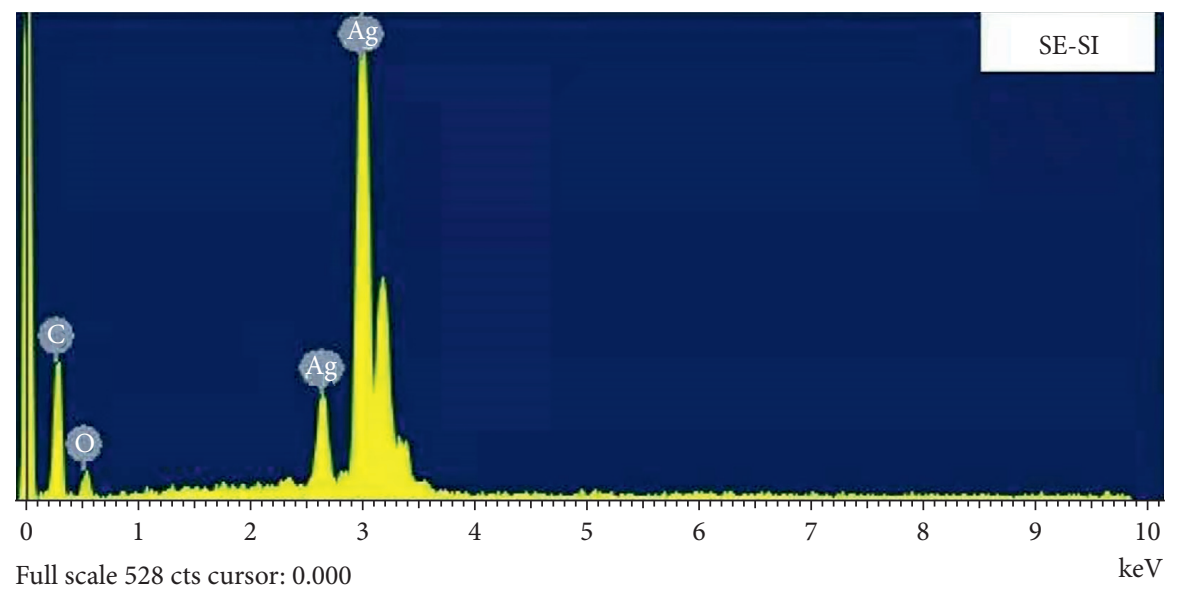

FIGURE 8: EDX micrograph of the synthesized silver nanoparticles adapted from [75].

develop novel antibacterial agents with good potency against MDR strains is of great importance [78]. AgNPs possess some features that can inhibit the growth of the MDR organism. The concentration, shape, colloidal state, and size are the major parameter that determine the antibacterial efficacy of AgNPs [79]. It has been established by researchers that the lower the size of AgNPs, the higher its stability and biocompatibility. The effectiveness of AgNPs against bacteria, fungi, and viruses has been established. The antibacterial activity of AgNPs has been recorded to be greater than that of silver nitrate [80]. AgNPs with smaller particle size are found more lethal because of their larger surface area and easy adsorption. Hence, AgNPs toxicity depends largely on size $[80,81]$. The ability of AgNPs to form an attachment on the bacterial cell wall and membrane, its capability in destruction of the structures within the cell, production of reactive oxygen species, and free radicals that stimulate cellular toxicity and oxidative stress and regulation of the signal transduction pathway are the distinct antibacterial actions of AgNPs [82]. When microorganisms are treated with AgNPs, AgNPs binds on the cell wall of the pathogen and causes the shrinkage of the cytoplasm and busting of the 
TABLE 3: The antibacterial activities of AgNPs synthesized from some plants extracts.

\begin{tabular}{|c|c|c|c|c|c|}
\hline $\begin{array}{l}\mathrm{S} / \\
\mathrm{N}\end{array}$ & Plant extract & Plant parts & $\begin{array}{c}\text { Zones of inhibition } \\
(\mathrm{mm})\end{array}$ & Bacterial strains & Ref. \\
\hline 1 & Althaea officinalis & Flower & $15-18$ & Escherichia coli and Staphylococcus aureus & [86] \\
\hline 2 & Thymus vulgaris & Leaf & $16-18$ & E. coli and S. aureus & [86] \\
\hline 3 & Mentha pulegium & Leaf & $16-18$ & E. coli and S. aureus & [86] \\
\hline 4 & Gleichenia pectinata & $\begin{array}{l}\text { Whole } \\
\text { plant }\end{array}$ & $5-15$ & $\begin{array}{c}\text { Pseudomonas aeruginosa, Klebsiella pneumonia, and Candida } \\
\text { albicans }\end{array}$ & [87] \\
\hline 5 & Berberis vulgaris & Root & $3-5$ & E. coli and S. aureus & [46] \\
\hline 6 & Saraca asoca & Leaf & 10 & Staphylococci aures, Streptococci pyogens, and Salmonella typhi & [88] \\
\hline 7 & $\begin{array}{l}\text { Glycosmis } \\
\text { mauritiana }\end{array}$ & Leaf & $7-19$ & $\begin{array}{c}\text { Bacillus cereus, B. subtilis, Enterococcus faecalis, E. coli, and } \\
\text { K. pneumonia }\end{array}$ & [89] \\
\hline 8 & Moringa oleifera & Leaf & $12-25$ & S. aureus, E. faecalis, E. coli, $P$. aeruginosa, and $K$. pneumoniae & [90] \\
\hline 9 & Olive europaea & Leaf & $18-21$ & Staphylococcus aureus, Escherichia coli, and Salmonella enterica & [91] \\
\hline 10 & Salvia rosmarinus & Leaf & $9-13$ & Staphylococcus aureus, Escherichia coli, and Salmonella enterica & [91] \\
\hline 11 & Amaranthus tricolor & Leaf & $7.8-11.8$ & Escherichia coli & [92] \\
\hline 12 & Musa balbisiana & Leaf & $6-16$ & Bacillus subtilis and E. coli cultures & [93] \\
\hline 13 & Azadirachta indica & Leaf & $8-14$ & Bacillus subtilis & [27] \\
\hline 14 & Ocimum tenuiflorum & Leaf & $8-14$ & E. coli cultures & [27] \\
\hline 15 & Salvia spinosa & Seed & $12-16$ & Bacillus subtilis, Bacillus vallismortis, and Escherichia coli & [27] \\
\hline 16 & Malachra capitata & Leaf & $14-21$ & $\begin{array}{c}\text { Bacillus subtilis, Micrococcus luteus, Staphylococcus aureus, and } \\
\text { Pseudomonas aeruginosa }\end{array}$ & [94] \\
\hline 17 & Tectona grand & Seed & $12-20$ & B. cereus, S. aureus, and E. coli & [25] \\
\hline 18 & Garcinia mangostana & Fruit & $12-18$ & Staphylococcus sp., Bacillus sp. Klebsiella sp., and Pseudomonas sp. & [95] \\
\hline 19 & $\begin{array}{l}\text { Zanthoxylum } \\
\text { chalybeum }\end{array}$ & Root & $0.83-2.67$ & B. subtilis, E. coli, and $P$. aeruginosa & [96] \\
\hline 20 & Azadirachta indica & Leaf & $11-13$ & E. coli, K. pneumonia, $P$. aeruginosa, and $S$. aureus & [97] \\
\hline 21 & Camellia sinensis & Leaf & $11-18$ & Escherichia coli & [97] \\
\hline 22 & Mangifera indica & Peel & $12-19$ & Klebsiella pneumonia & [97] \\
\hline 23 & Syzygium cumini & Bark & $10-12$ & Escherichia coli and Bacillus subtilis. & [98] \\
\hline 24 & $\begin{array}{l}\text { Plectranthus } \\
\text { amboinicus }\end{array}$ & Leaf & $0-31$ & P. vulgaris, $P$. aeruginosa, B. subtilis, and $S$. aureus & [99] \\
\hline
\end{tabular}

$\mathrm{mm}$, millimeter.

cell wall [83]. The interaction of AgNPs with sulfur-containing enzyme such as O-acetylserine sulfhydrylase (CysK) changes destroys the cell wall morphology of the pathogen [84]. AgNPs has been recommended for the treatment of infections caused by Gram-negative bacteria because AgNPs display higher toxicity against the Gram-negative bacteria than Gram-positive bacteria because of the thinner cell wall and small amount of peptidoglycan they have [85]. The antibacterial activities of AgNPs synthesized from some plants extracts are shown in Table 3.

\section{Conclusion}

Over the years, many efforts have been invested into the development of safer method of synthesizing AgNPs. The morphological evaluation of AgNPs synthesized from plants using various characterization techniques revealed variations in size, crystallinity, and shape distribution which is a huge challenge and a major limitation. This suggests that the regulation of silver salt concentration, volume of plant extract, $\mathrm{pH}$ value of the solution, reaction temperature, and time have crucial roles in procurement of Ag NPs with uniform size and shape distribution. All the same, the production of AgNPs with uniform morphological properties is of importance. Furthermore, the identification of the exact functional group in the biomolecules of plant accountable for the reduction and stabilization of silver ion required more investigation. Aside from the investigation of the antibacterial potency of AgNPs, the in vivo examination should also be investigated to assess their biocompatibility and toxicity level so that novel and potential therapeutic agent for bacterial can be produced.

\section{Conflicts of Interest}

The authors declare that they have no conflicts of interest.

\section{References}

[1] A. H. Holmes, L. S. P. Moore, A. Sundsfjord et al., "Understanding the mechanisms and drivers of antimicrobial resistance," The Lancet, vol. 387, pp. 176-187, Article ID 10014, 2016.

[2] J. Y. Song and B. S. Kim, "Rapid biological synthesis of silver nanoparticles using plant leaf extracts," Bioprocess and Biosystems Engineering, vol. 32, no. 1, p. 79, 2009.

[3] Y. Zhang, X. Cheng, Y. Zhang, X. Xue, and Y. Fu, "Biosynthesis of silver nanoparticles at room temperature using aqueous aloe leaf extract and antibacterial properties," Colloids and Surfaces A: Physicochemical and Engineering Aspects, vol. 423, pp. 63-68, 2013.

[4] A. Folorunso, A. K. Akintelu, S. Ajayi, B. Abiola, I. Abdusalam, and A. Morakinyo, "Biosynthesis, characterization and antimicrobial activity of gold nanoparticles from 
leaf extracts of Annona muricata," Journal of Nanostructure in Chemistry, vol. 9, no. 2, pp. 111-117, 2019 b.

[5] A. Asthana, R. Verma, A. K. Singh, M. A. B. Hasan Susan, and R. Adhikari, "Silver nanoparticle entrapped calcium-alginate beads for Fe (II) removal via adsorption," in Macromolecular SymposiaWiley Online Library, Hoboken, NJ, USA, 2016.

[6] S. K. Das, M. M. R. Khan, A. K. Guha, A. R. Das, and A. B. Mandal, "Silver-nano biohybride material: synthesis, characterization and application in water purification," Bioresource Technology, vol. 124, pp. 495-499, 2012.

[7] H. Ping, M. Zhang, H. Li et al., "Visual detection of melamine in raw milk by label-free silver nanoparticles," Food Control, vol. 23, no. 1, pp. 191-197, 2012.

[8] N. Vigneshwaran, A. A. Kathe, P. V. Varadarajan, R. P. Nachane, and R. H. Balasubramanya, "Functional finishing of cotton fabrics using silver nanoparticles," Journal of Nanoscience and Nanotechnology, vol. 7, no. 6, pp. 1893-1897, 2007a.

[9] Y. He, Z. Du, Z. Tang et al., "Green synthesis of silver nanoparticles by Chrysanthemum morifolium Ramat. extract and their application in clinical ultrasound gel," International Journal of Nanomedicine, vol. 8, p. 1809, 2013.

[10] D. G. Thompson, A. Enright, K. Faulds, W. E. Smith, and D. Graham, "Ultrasensitive DNA detection using Oligonucleotide-Silver nanoparticle conjugates," Analytical Chemistry, vol. 80, no. 8, pp. 2805-2810, 2008.

[11] S. Lin, R. Huang, Y. Cheng, J. Liu, B. L. T. Lau, and M. R. Wiesner, "Silver nanoparticle-alginate composite beads for point-of-use drinking water disinfection," Water Research, vol. 47, no. 12, pp. 3959-3965, 2013.

[12] M. U. Rashid, M. K. H. Bhuiyan, and M. E. Quayum, "Synthesis of silver nano particles (Ag-NPs) and their uses for quantitative analysis of vitamin C tablets," Dhaka University Journal of Pharmaceutical Sciences, vol. 12, no. 1, pp. 29-33, 2013.

[13] S. A. Akintelu, A. S. Folorunso, F. A. Folorunso, and A. K. Oyebamiji, "Green synthesis of copper oxide nanoparticles for biomedical application and environmental remediation," Heliyon, vol. 6, pp. 1-12, Article ID e04508, 2020.

[14] S. A. Akintelu and A. S. Folorunso, "A review on green synthesis of zinc oxide nanoparticles using plant extracts and its biomedical applications," BioNanoScience, vol. 10, 2020.

[15] G. K. Rose, R. Soni, P. Rishi, and S. K. Soni, "Optimization of the biological synthesis of silver nanoparticles using Penicillium oxalicum GRS-1 and their antimicrobial effects against common food-borne pathogens," Green Processing and Synthesis, vol. 8, no. 1, pp. 144-156, 2019.

[16] A. Shahzad, H. Saeed, M. Iqtedar et al., "Size-controlled production of silver nanoparticles by Aspergillus fumigatus BTCB10: likely antibacterial and cytotoxic effects," Journal of Nanomaterials, vol. 2019, Article ID 5168698, 14 pages, 2019.

[17] R. M. Elamawi, R. E. Al-Harbi, and A. A. Hendi, "Biosynthesis and characterization of silver nanoparticles using Trichoderma longibrachiatum and their effect on phytopathogenic fungi," Egyptian Journal of Biological Pest Control, vol. 28, no. 1, p. $28,2018$.

[18] P. Mukherjee, A. Ahmad, D. Mandal et al., "Fungus-mediated synthesis of silver nanoparticles and their immobilization in the mycelial matrix: a novel biological approach to nanoparticle synthesis," Nano Letters, vol. 1, no. 10, pp. 515-519, 2001.

[19] S. A. Akintelu and A. S. Folorunso, "Characterization and antimicrobial investigation of synthesized silver nanoparticles from Annona muricata leaf extracts," HSOA Journal of Nanotechnology: Nanomedicine \& Nanobiotechnology, vol. 6, pp. 1-5, 2019.
[20] S. A. Akintelu, A. S. Folorunso, A. K. Oyebamiji, and E. A. Erazua, "Antibacterial potency of silver nanoparticles synthesized using Boerhaavia diffusa leaf extract as reductive and stabilizing agent," International Journal of Pharma Sciences and Research, vol. 10, no. 12, pp. 374-380, 2019.

[21] S. S. Shankar, A. Rai, B. Ankamwar, A. Singh, A. Ahmad, and M. Sastry, "Biological synthesis of triangular gold nanoprisms," Nature Materials, vol. 3, no. 7, p. 482, 2004.

[22] L. Castro, M. L. Blázquez, J. A. Muñoz, F. González, C. GarcíaBalboa, and A. Ballester, "Biosynthesis of gold nanowires using sugar beet pulp," Process Biochemistry, vol. 46, no. 5, pp. 1076-1082, 2011.

[23] J. Bhaumik, N. S. Thakur, P. K. Aili, A. Ghanghoriya, A. K. Mittal, and U. C. Banerjee, "Bioinspired nanotheranostic agents: synthesis, surface functionalization, and antioxidant potential," ACS Biomaterials Science \& Engineering, vol. 1, no. 6, pp. 382-392, 2015

[24] S. A. Akintelu, A. S. Folorunso, and O. T. Ademosun, "Instrumental characterization and antibacterial investigation of silver nanoparticles synthesized from Garcinia kola leaf," Journal of Drug Delivery and Therapeutics, vol. 9, no. 6, pp. 58-64, 2019.

[25] A. K. Mittal, Y. Chisti, and U. C. Banerjee, "Synthesis of metallic nanoparticles using plant extracts," Biotechnology Advances, vol. 31, no. 2, pp. 346-356, 2013.

[26] M. T. El-Saadony, N. A. El-Wafai, H. I. A. El-Fattah, and S. A. Mahgoub, "Biosynthesis, optimization and characterization of silver nanoparticles using a soil isolate of Bacillus pseudomycoides MT32 and their antifungal activity against some pathogenic fungi," Advances in Animal and Veterinary Sciences, vol. 7, no. 4, pp. 238-249, 2019.

[27] P. Saba, G. Maryam, and B. Saeid, "Green synthesis of silver nanoparticles using the plant extract of Salvia spinosa grown in vitro and their antibacterial activity assessment," Journal of Nanostructure in Chemistry, vol. 9, pp. 1-9, 2019.

[28] K. Narayanaswamy, R. Athimoolam, and J. Ayyavoo, "Green synthesis of silver nanoparticles using leaf extracts of Clitoria ternatea and Solanum nigrum and study of its antibacterial effect against common nosocomial pathogens," Journal of Nanoscience, vol. 2015, Article ID 928204, 8 pages, 2015.

[29] A. K. Mittal, Y. Chisti, and U. C. Banerjee, "Synthesis of metallic nanoparticles using plant extracts," Biotechnology Advances, vol. 31, no. 2, pp. 346-356, 2013.

[30] S. Iravani and B. Zolfaghari, "Green synthesis of silver nanoparticles using Pinus eldarica bark extract," BioMed Research International, vol. 2013, Article ID 639725, 5 pages, 2013.

[31] S. S. Birla, S. C. Gaikwad, A. K. Gade, and M. K. Rai, "Rapid synthesis of silver nanoparticles fromFusarium oxysporumby optimizing physicocultural conditions," The Scientific World Journal, vol. 2013, Article ID 796018, 12 pages, 2013.

[32] T. Khan, M. A. Khan, and A. Nadhman, "Synthesis in plants and plant extracts of silver nanoparticles with potent antimicrobial properties: current status and future prospects," Applied Microbiology and Biotechnology, vol. 99, no. 23, pp. 9923-9934, 2015.

[33] R. Kumar, S. M. Roopan, A. Prabhakarn, V. G. Khanna, and S. Chakroborty, "Agricultural waste Annona squamosa peel extract: biosynthesis of silver nanoparticles," Spectrochimica Acta Part A: Molecular and Biomolecular Spectroscopy, vol. 90, pp. 173-176, 2012.

[34] Y. Park, H. J. Noh, L. Han et al., “Artemisia capillaris extracts as a green factory for the synthesis of silver nanoparticles with antibacterial activities," Journal of Nanoscience and Nanotechnology, vol. 12, no. 9, pp. 7087-7095, 2012. 
[35] V. Kim and D. S. V. G. K. Kaladhar, "Review: green synthesis of silver and gold nanoparticles," Middle-East Journal of Scientific Research, vol. 19, pp. 834-842, 2014.

[36] R. K. Das and S. K. Brar, "Plant mediated green synthesis: modified approaches," Nanoscale, vol. 5, no. 21, pp. 10155-10162, 2013.

[37] M. K. Swamy, K. M. Sudipta, K. Jayanta, and S. Balasubramanya, "The green synthesis, characterization, and evaluation of the biological activities of silver nanoparticles synthesized from Leptadenia reticulata leaf extract," Applied Nanoscience, vol. 5, pp. 1-9, 2014.

[38] H. Najeh, M. B. Abbas, and J. Amal, "Biosynthesis of silver nanoparticles by mentha spicata ethanolic leaves extract and investigation the antibacterial activity," AIP Conference Proceedings, vol. 2144, Article ID 040009, 2019.

[39] L. Yee-Shing, C. Yung-Chung, and C. Hui-Huang, "Silver nanoparticle biosynthesis by using phenolic acids in rice husk extract as reducing agents and dispersants," Journal of Food and Drug Analysis, vol. 26, pp. 649-656, 2018.

[40] J. Balavijayalakshmi and V. Ramalakshmi, "Carica papaya peel mediated synthesis of silver nanoparticles and its antibacterial activity against human pathogens," Journal of Applied Research and Technology, vol. 15, no. 5, pp. 413-422, 2017.

[41] M. Z. H. Khan, F. K. Tareq, M. A. Hossen, and M. N. A. M. Roki, "Green synthesis and characterization of silver nanoparticles using coriandrum sativum leaf extract," Journal of Engineering Science and Technology, vol. 13, no. 1, pp. 158-166, 2018.

[42] Y. Chen, T. Jingchun, L. Xiaomei, R. Xinwei, Z. Meinan, and W. Lan, "Green biosynthesis of silver nanoparticles using Eriobotrya Japonica (thunb.) leaf extract for reductive catalysis," Materials, vol. 12, 2019.

[43] P. Logeswari, "Synthesis of silver nanoparticles using plants extract and analysis of their antimicrobial property," Journal of Saudi Chemical Society, vol. 48, 2012.

[44] L. Le Ngoc, P. Nguyen, and N. Dieu, "Microwave assisted green synthesis of silver nanoparticles using mulberry leaves extract and silver nitrate solution," Technologies, vol. 7, p. 7, 2019.

[45] O. M. S. Ibrahim and L. W. Omar, "Biosynthesis and characterization of silver nanoparticles by silybum marianum (silymarin) fruit extract," Advances in Animal and Veterinary Sciences, vol. 7, no. 2, pp. 122-130, 2019.

[46] B. Mahmoodreza, H. P. Ayat, N. Ali, Z. Masood, and M. Roya, "Aliyar M Facile green synthesis of silver nanoparticles using Berberis vulgaris leaf and root aqueous extract and its antibacterial activity," International Journal of Biological Macromolecules, vol. 124, pp. 148-154, 2019.

[47] H. Korbekandi, M. R. Chitsazi, G. Asghari, R. Bahri Najafi, A. Badii, and S. Iravani, "Green biosynthesis of silver nanoparticles using Quercus brantii (oak) leaves hydroalcoholic extract," Pharmaceutical Biology, vol. 53, no. 6, pp. 807-812, 2015.

[48] A. Saravanakumar, M. M. Peng, M. Ganesh, J. Jayaprakash, M. Mohankumar, and H. T. Jang, "Low-cost and eco-friendly green synthesis of silver nanoparticles using Prunus japonica (Rosaceae) leaf extract and their antibacterial, antioxidant properties," Artificial Cells, Nanomedicine, and Biotechnology, vol. 45, no. 6, 2016.

[49] B. Sadeghi, A. Rostami, and S. S. Momeni, "Facile green synthesis of silver nanoparticles using seed aqueous extract of Pistacia atlantica and its antibacterial activity," Spectrochimica
Acta Part A: Molecular and Biomolecular Spectroscopy, vol. 134, pp. 326-332, 2015.

[50] T. Rajagopal, I. A. Jemimah, P. Ponmanickam, and M. Ayyanar, "Synthesis of silver nanoparticles using Catharanthus roseus root extract and its larvicidal effects," Journal of Environmental Biology, vol. 36, no. 6, p. 1283, 2015.

[51] E. Rodr_1guez-Le_on, R. I niguez-Palomares, R. E. Navarro et al., "Synthesis of silver nanoparticles using reducing agents obtained from natural sources (Rumex hymenosepalus extracts)," Nanoscale Research Letters, vol. 8, pp. 1-9, 2013.

[52] S. Medda, A. Hajra, U. Dey, P. Bose, and N. K. Mondal, "Biosynthesis of silver nanoparticles from Aloe vera leaf extract and antifungal activity against Rhizopus sp. and Aspergillus sp," Applied Nanoscience, vol. 5, no. 7, pp. 875-880, 2015.

[53] N. H. Mohamed, M. A. Ismail, W. M. Abdel-Mageed, and A. A. Mohamed Shoreit, "Antimicrobial activity of latex silver nanoparticles using Calotropis procera," Asian Pacific Journal of Tropical Biomedicine, vol. 4, no. 11, pp. 876-883, 2014.

[54] D. Nayak, S. Pradhan, S. Ashe, P. R. Rauta, and B. Nayak, "Biologically synthesised silver nanoparticles from three diverse family of plant extracts and their anticancer activity against epidermoid A431 carcinoma," Journal of Colloid and Interface Science, vol. 457, pp. 329-338, 2015.

[55] P. R. Sre, M. Reka, R. Poovazhagi, M. A. Kumar, and K. Murugesan, "Antibacterial and cytotoxic effect of biologically synthesized silver nanoparticles using aqueous root extract of Erythrina indica lam," Spectrochimica Acta A Molecular and Biomolecular Spectroscopy, vol. 135, pp. 1137-1144, 2015.

[56] P. Palaniappan, G. Sathishkumar, and R. Sankar, "Fabrication of nano-silver particles using Cymodocea serrulata and its cytotoxicity effect against human lung cancer A549 cells line," Spectrochimica Acta Part A: Molecular and Biomolecular Spectroscopy, vol. 138, pp. 885-890, 2015.

[57] Y. He, Z. Du, S. Y. Ma et al., "Effects of green-synthesized silver nanoparticles on lung cancer cells in vitro and grown as xenograft tumors in vivo," International Journal of Nanomedicine, vol. 11, p. 1879, 2016.

[58] A. B. Liu, G. Balasubramani, R. R. Ramkumar, M. D. Balakumaran, P. T. Kalaichelvan, and P. Perumal, "Structural characterization, antioxidant and in vitro cytotoxic properties of seagrass, Cymodocea serrulata (R.Br.) Asch. \& Magnus mediated silver nanoparticles," Journal of Photochemistry and Photobiology B: Biology, vol. 153, pp. 145-152, 2015.

[59] R. Sowmiya and M. Rashidipour, "Green synthesis of silver nanoparticles using extract of oak fruit hull (Jaft): synthesis and in vitro cytotoxic effect on MCF-7 cells," International Journal of Breast Cancer, vol. 2015, Article ID 846743, 6 pages, 2015.

[60] B. Kumar, K. Smita, R. Seqqat, K. Benalcazar, M. Grijalva, and L. Cumbal, "In vitro evaluation of silver nanoparticles cytotoxicity on hepatic cancer (Hep-G2) cell line and their antioxidant activity: green approach for fabrication and application," Journal of Photochemistry and Photobiology B: Biology, vol. 159, pp. 8-13, 2016.

[61] R. Mata, J. Reddy Nakkala, and S. Rani Sadras, "Catalytic and biological activities of green silver nanoparticles synthesized from Plumeria alba (frangipani) flower extract," Materials Science and Engineering: C, vol. 51, pp. 216-225, 2015.

[62] B. Venkatesan, V. Subramanian, A. Tumala, and E. Vellaichamy, "Rapid synthesis of biocompatible silver nanoparticles using aqueous extract of Rosa damascena petals 
and evaluation of their anticancer activity," Asian Pacific Journal of Tropical Medicine, vol. 7, no. 1, pp. 294-300, 2014.

[63] R. Manikandan, B. Manikandan, T. K. Raman et al., "Biosynthesis of silver nanoparticles using ethanolic petals extract of Rosa indica and characterization of its antibacterial, anticancer and anti-inflammatory activities," Spectrochimica Acta Part A: Molecular and Biomolecular Spectroscopy, vol. 138, pp. 120-129, 2015.

[64] K. Alaqad and T. A. Saleh, "Gold and silver nanoparticles: synthesis methods, characterization routes and applications towards drugs," Journal of Environmental \& Analytical Toxicology, vol. 6, no. 4, pp. 1-10, 2016.

[65] B. K. Mehta, M. Chhajlani1, and B. D. Shrivastava, "Green synthesis of silver nanoparticles and their characterization by XRD," IOP Conference Series: Journal of Physics, vol. 836, 2017.

[66] T. Klein, E. Buhr, and C. Georg Frase, "TSEM," Advances in Imaging and Electron Physics, vol. 171, pp. 297-356, 2012.

[67] J. Arunagirinathan and V. Ramalakshmi, "Carica papaya peel mediated synthesis of silver nanoparticles and its antibacterial activity against human pathogens," Journal of Applied Research and Technology, vol. 15, no. 5, pp. 413-422, 2017.

[68] S. Iravani, "Green synthesis of metal nanoparticles using plants," Green Chemistry, vol. 13, no. 10, pp. 2638-2650, 2011.

[69] V. K. Vidhu, S. A. Aromal, and D. Philip, "Green synthesis of silver nanoparticles using Macrotyloma uniflorum," Spectrochimica Acta Part A: Molecular and Biomolecular Spectroscopy, vol. 83, no. 1, pp. 392-397, 2011.

[70] U. B. Jagtap and V. A. Bapat, "Green synthesis of silver nanoparticles using Artocarpus heterophyllus Lam. seed extract and its antibacterial activity," Industrial Crops and Products, vol. 46, pp. 132-137, 2013.

[71] P. Shanmuga Praba, V. S. Vasantha, J. Jeyasundari, and Y. Brightson Arul Jacob, "Synthesis of plant-mediated silver nanoparticles using Ficus microcarpa leaf extract and evaluation of their antibacterial activities," European Chemical Bulletin, vol. 4, no. 3, pp. 117-120, 2015.

[72] S. A. Akintelu, B. Yao, and A. S. Folorunso, "Green synthesis, characterization, and antibacterial investigation of synthesized gold nanoparticles (AuNPs) from Garcinia kola pulp extract," Plasmonics, vol. 15, no. 5, 2020.

[73] P. Phanjom, A. Sultana, H. Sarma, J. Ramchiary, K. Goswami, and P. Baishya, "Plant-mediated synthesis of silver nanoparticles using Elaeagnus latifolia leaf extract," Digest Journal of Nanomaterials and Biostructures, vol. 7, no. 3, pp. 1117$1123,2012$.

[74] M. Oves, M. Aslam, M. A. Rauf et al., "Antimicrobial and anticancer activities of silver nanoparticles synthesized from the root hair extract of Phoenix dactylifera," Materials Science and Engineering: $C$, vol. 89, pp. 429-443, 2018.

[75] E. K. Kambale, C. I. Nkanga, B. I Mutonkole et al., "Green synthesis of antimicrobial silver nanoparticles using aqueous leaf extracts from three Congolese plant species (Brillantaisia patula, Crossopteryx febrifuga and Senna siamea)," Heliyon, vol. 6, Article ID e04493, 2020.

[76] S. A. Akintelu and A. S. Folorunso, "Biosynthesis, characterization and antifungal investigation of $\mathrm{Ag}-\mathrm{Cu}$ nanoparticles from bark extracts of garcina kola," Stem Cell, vol. 10, no. 4, pp. 30-37, 2019.

[77] N. Hikmah, N. F. Idrus, J. Jai, and A. Hadi, "Synthesis and characterization of silver copper core- shell nanoparticles using polyol method for antimicrobial agent," IOP Conference Series: Earth Environmental Science, vol. 36, Article ID 012050, 2016.
[78] A. Kapil, "The challenge of antibiotic resistance: need to contemplate," The Indian Journal of Medical Research, vol. 121, no. 2, pp. 83-91, 2005.

[79] S. Ankanna, T. N. V. K. V. Prasad, E. K. Elumalai, and N. Savithramma, "Production of biogenic silver nanoparticles using Boswellia ovalifoliolata stem bark," Digest Journal of Nanomaterials Biostructures, vol. 5, no. 2, pp. 369-372, 2010.

[80] U. Klueh, V. Wagner, S. Kelly, A. Johnson, and J. D. Bryers, "Efficacy of silver-coated fabric to prevent bacterial colonization and subsequent device-based biofilm formation," Journal of Biomedical Materials Research, vol. 53, no. 6, pp. 621-631, 2000.

[81] L. Cui, P. Chen, S. Chen et al., "In situ study of the antibacterial activity and mechanism of action of silver nanoparticles by surface-enhanced Raman spectroscopy," Analytical Chemistry, vol. 85, no. 11, pp. 5436-5443, 2013.

[82] T. C. Dakal, A. Kumar, R. S. Majumdar, and V. Yadav, "Mechanistic basis of antibacterial actions of silver nanoparticles," Frontiers in Microbiology, vol. 7, p. 1831, 2016.

[83] A. R. Nalwade and A. A. Jadhav, "Biosynthesis of silver nanoparticles using leaf extract of Daturaalba Nees and evaluation of their antibacterial activity," Archives of Applied Science Research, vol. 5, pp. 45-49, 2013.

[84] S. Ghosh, S. Patil, M. Ahire et al., "Synthesis of silver nanoparticles using Dioscoreabulbifera tuber extract and evaluation of its synergistic potential in combination with antibacterial agents," International Journal of Nanomedicine, vol. 7, p. 483, 2012.

[85] D. Sumon and C. Tamalika, "A review on green synthesis of silver nanoparticle and zinc oxide nanoparticle from different plants extract and their antibacterial activity against multidrug resistant bacteria," Journal of Innovations in Pharmaceutical and Biological Sciences, vol. 5, no. 4, pp. 63-73, 2018.

[86] A. Jafari, L. Pourakbar, K. Farhadi, L. Mohamadgolizad, and Y. Goosta, "Biological synthesis of silver nanoparticles and evaluation of antibacterialand antifungal properties of silver and copper nanoparticles," Turkish Journal of Biology, vol. 39, pp. 556-561, 2015.

[87] G. F. A. Abiola, O. D. Adewumi, O. O. Kabir, O. A. Adeyinka, and P. F. Ojo, "Green synthesis of silver nanoparticles using terrestrial fern (Gleichenia Pectinata (Willd.) C. Presl.): characterization and antimicrobial studies," Heliyon, vol. 5, Article ID e01543, 2019.

[88] S. Fatema, M. Shirsat, M. Farooqui, and P. Mohd Arif, "Biosynthesis of Silver nanoparticle using aqueous extract of Saraca asoca leaves, its characterization and antimicrobial activity," International Journal of Nano Dimension, vol. 10, no. 2, pp. 163-168, 2019.

[89] S. Amutha and S. Sridhar, "Green synthesis of magnetic iron oxide nanoparticle using leaves of Glycosmis mauritiana and their antibacterial activity against human pathogens," Journal of Innovations in Pharmaceutical and Biological Sciences, vol. 5, no. 2, pp. 22-26, 2018.

[90] S. M. Jerushka, "Green synthesis of silver nanoparticles from Moringa oleifera leaf extracts and its antimicrobial Potential," Advances in Natural Sciences: Nanosciences and Nanotechnology, vol. 9, Article ID 015011, 2018.

[91] M. A. AbuDalo, I. R. Al-Mheidat, A. W. Al-Shurafat, C. Grinham, and V. Oyanedel-Craver, "Synthesis of silver nanoparticles using a modified Tollens' method in conjunction with phytochemicals and assessment of their antimicrobial activity," PeerJ, vol. 7, Article ID e6413, 2019.

[92] F. Is and Z. H. V. I. Aftrid, "Characteristics and antibacterial activity of green synthesized silver nanoparticles using red 
spinach (Amaranthus Tricolor L.) leaf extract," Green Chemistry Letters and Reviews, vol. 12, no. 1, pp. 25-30, 2019.

[93] B. Priya, S. Mantosh, M. Aniruddha, and D. Papita, "Leaf extract mediated green synthesis of silver nanoparticles from widely available Indian plants: synthesis, characterization, antimicrobial property and toxicity analysis," Bioresources and Bioprocessing, vol. 1, pp. 1-10, 2014.

[94] G. M. Srirangam and R. K. Parameswara, "Synthesis and charcterization of silver nanoparticles from the leaf extract of malachra capitata (L.)," Rasayan Journal of Chemistry, vol. 10, no. 1, pp. 46-53, 2017.

[95] R. Nishanthi, S. Malathi, S. John Paul, and P. Palani, "Green synthesis and characterization of bioinspired silver, gold and platinum nanoparticles and evaluation of their synergistic antibacterial activity after combining with different classes of antibiotics," Materials Science \& Engineering C, vol. 96, pp. 693-707, 2019.

[96] M. Courtie and W. Tinashe, "Green synthesis of silver nanoparticles using Zanthoxylum chalybeum and their antiprolytic and antibiotic properties Cogent," Chemistry, vol. 4, pp. 11-15, 2018.

[97] G. Y. Sapna, H. P. Sudeep, P. Pratima et al., "Green synthesis of silver nanoparticles from plant sources and evaluation of their antimicrobial activity," IJSRSET, vol. 4, no. 5, pp. 133139, 2018.

[98] E. C. Sekhar, K. S. V. Krishna, S. K. Madhu, and S. A. Bahadur, "Simple biosynthesis of silver nanoparticles from syzygium cumini stem bark aqueous extract and their spectrochemical and antimicrobial studies," Journal of Applied Pharmaceutical Science, vol. 8, no. 01, pp. 073-079, 2018.

[99] K. Niveditha and S. T. H. Green Synthesis, "Characterization and antimicrobial activity of silver nanoparticles from plectranthus amboinicus plant extracts," Indian Journal of Medical Research and Pharmaceutical Sciences, vol. 5, no. 3, pp. 41-51, 2018. 